\title{
JRC2016-5817
}

\section{CONVENTIONAL LOCOMOTIVE COUPLING TESTS: TEST REQUIREMENTS AND PRE-TEST ANALYSIS}

\author{
Patricia Llana \\ David Tyrell \\ Volpe National Transportation Systems Center \\ United States Department of Transportation \\ Cambridge, Massachusetts, USA \\ Przemyslaw Rakoczy \\ Transportation Technology Center, Inc. \\ Pueblo, Colorado, USA
}

\begin{abstract}
Research to develop new technologies for increasing the safety of passengers and crew in rail equipment is being directed by the Federal Railroad Administration's (FRA's) Office of Research, Development, and Technology. Crash energy management (CEM) components which can be integrated into the end structure of a locomotive have been developed: a pushback coupler and a deformable anti-climber. These components are designed to inhibit override in the event of a collision. The results of vehicle-to-vehicle override, where the strong underframe of one vehicle, typically a locomotive, impacts the weaker superstructure of the other vehicle, can be devastating. The components are designed to improve crashworthiness for equipped locomotives in a wide range of potential collisions, including collisions with conventional locomotives, conventional cab cars, and freight equipment.

Concerns have been raised in discussions with industry that push-back couplers may trigger prematurely, and may require replacement due to unintentional activation as a result of service loads. It has been shown analytically that push back coupler trigger loads exceed the service load capacity of conventional couplers and draft gears. Two sets of coupling tests are planned to demonstrate this, one with a locomotive equipped with conventional draft gear and coupler and another with a locomotive equipped with a pushback coupler. These tests allow for comparison of conventional with CEM-equipped locomotive measured performance during coupling. In addition to the coupling tests, car-to-car compatibility tests of equipped
\end{abstract}

locomotives and a train-to-train test are also planned. This arrangement of tests allows for evaluation of the CEM-equipped locomotive performance, as well as comparison of measured with simulated locomotive performance in the car-to-car and train-to-train tests. In the coupling tests of conventional equipment, the maximum coupling speed for which there is no damage to either vehicle will be measured. A moving locomotive will be coupled to a standing cab car. The coupling speed for the first test will be $2 \mathrm{mph}$, the second test $4 \mathrm{mph}$, and the tests will continue with the speed incrementing by $2 \mathrm{mph}$ until damage occurs to either vehicle.

This paper describes the test requirements and analysis predictions for the coupling tests of conventional equipment. The equipment to be tested, track conditions, test procedures, and measurements to be made are described. A one-dimensional model for predicting the longitudinal forces acting on the equipment and couplers has been developed, along with preliminary predictions for the conventional coupling tests. It is expected that damage will occur for coupling speeds between 6 and $8 \mathrm{mph}$.

\section{BACKGROUND}

The Office of Research, Development, and Technology of the Federal Railroad Administration (FRA) and the Volpe Center are continuing to evaluate new technologies for increasing the safety of passengers and operators in rail equipment. In recognition of the importance of override prevention in train-totrain collisions in which one of the vehicles is a locomotive [1, $2,3]$, and in light of the success of crash energy management 
technologies in passenger trains [4], FRA seeks to evaluate the effectiveness of components that are integrated into the end structure of a locomotive that are specifically designed to mitigate the effects of a collision and, in particular, to prevent override of one of the lead vehicles onto the other [5].

A research program has been recently conducted that developed, fabricated and tested two crash energy management (CEM) components for the forward end of a locomotive: (1) a deformable anti-climber, and (2) a push-back coupler [6, 7]. Detailed designs for these components were developed, and the performance of each design was evaluated through large deformation dynamic finite element analysis (FEA). Two test articles were fabricated and individually dynamically tested by means of rail car impact into a test wall in order to verify certain performance characteristics of the two components relative to specific requirements. The tests were successful in demonstrating the effectiveness of the two design concepts. Test results were consistent with finite element model predictions in terms of energy absorption capability, force-displacement behavior and modes of deformation.

This research program will eventually integrate the two CEM components onto a locomotive in order to demonstrate that these components work together to mitigate the effects of a collision and prevent override [8]. A series of dynamic CEM coupling tests is planned to demonstrate that the push-back coupler will, or will not, trigger, depending on the proper conditions. However, before demonstrating the robustness of the push-back coupler (PBC), it is important to establish a baseline for conventional coupling to determine the maximum nondestructive conventional coupling speed. Therefore, conventional coupling tests will be conducted. The coupling tests will be conducted repeatedly with the same F40 locomotive and M1 passenger car, starting at $2 \mathrm{mph}$ for the first test, and increasing in increments of $2 \mathrm{mph}$ until damage occurs in either vehicle.

\section{CONVENTIONAL COUPLING TESTS REQUIREMENTS}

The conventional coupling tests will be conducted at the Transportation Technology Center (TTC) in Pueblo, Colorado. For these tests, the locomotive will impact the stationary M1 at increasing speeds until damage occurs. The coupling tests will be conducted repeatedly with the same conventional F40 locomotive and M1 passenger car, starting at $2 \mathrm{mph}$ for the first test, and increasing in increments of $2 \mathrm{mph}$ until damage occurs in either vehicle, as shown in Figure 1. For these impact tests, the M1 car will be braked.

The objective of this effort is to determine the maximum non-destructive conventional coupling speed by conducting conventional coupling tests. This will establish a baseline for comparison with future CEM coupling tests. The structural performance of the conventional coupler and the coupling vehicles will be measured and characterized under a range of dynamic coupling speeds until damage occurs in either vehicle.

The information desired from the conventional coupling tests includes the longitudinal, vertical and lateral accelerations of the equipment and the displacements of the couplers. Information is also sought on the sequence of events, e.g., timing of coupling and then bottoming of the draft gear. The equipment and components will be inspected carefully after each coupling test to ascertain the condition of the equipment and determine if any damage has occurred.

The force-crush characteristic (i.e., the load that the couplers and supporting structure develop during the coupling procedure) is a key characteristic of the couplers and the cars. One purpose of these tests is to take measurements for comparison with analytical predictions in order to validate that such predictions are accurate. Another comparison that will be made will be with the measurements taken for the PBC coupling tests.
Conventional F40

$2,4,6 m p h . . . V_{x}$

\section{M1 Cab Car}

$$
\mathrm{V}=0 \mathrm{mph}
$$

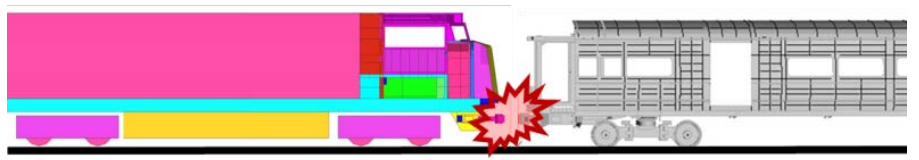

Figure 1. Schematic of coupling test initial conditions.

The equipment that will be used for the conventional coupling test will be a conventional F40 locomotive and an M1 passenger cab car. F40 locomotive \#202 will be used in the tests and can be seen in Figure 2.

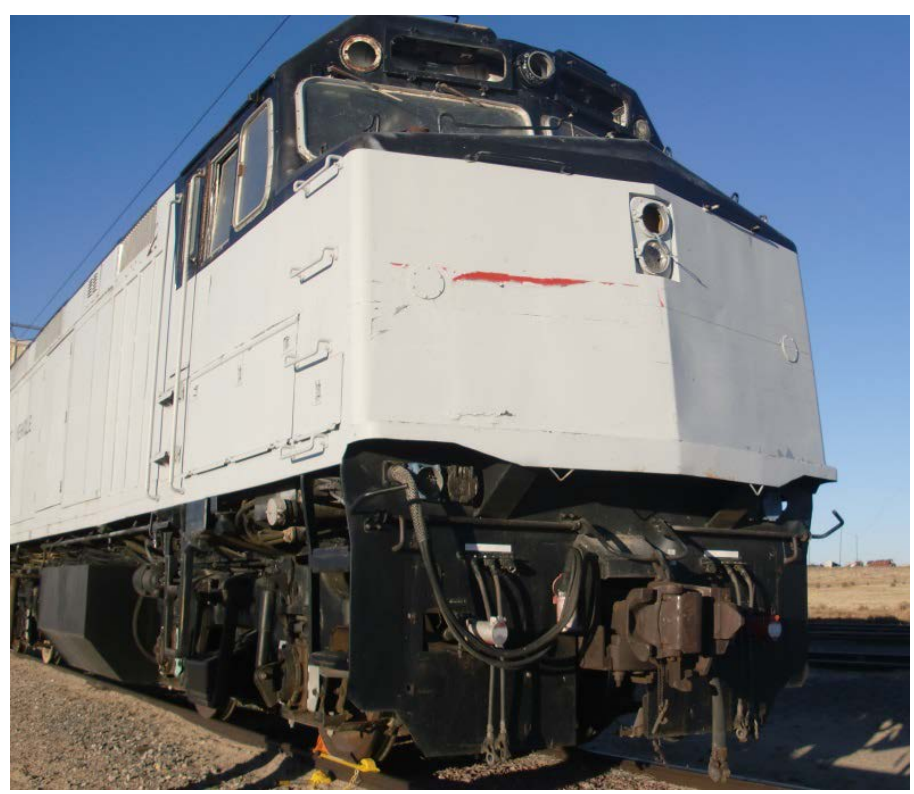

Figure 2. F40 locomotive \#202 will be used in the conventional coupling tests.

Figure 3 shows the F40 draft gear and yoke. The draft gear provides cushioning for longitudinal train loads and for coupling. The draft gear is double acting, in the sense that a single pack of rubber/metal plates provides cushioning in both buff and draft. These are key elements to be tested in the coupling tests. The load imparted to the locomotive is a function of the draft gear stiffness, as well as of the stiffness of the structure that supports the draft gear. All of these components will be highly loaded during the tests. 


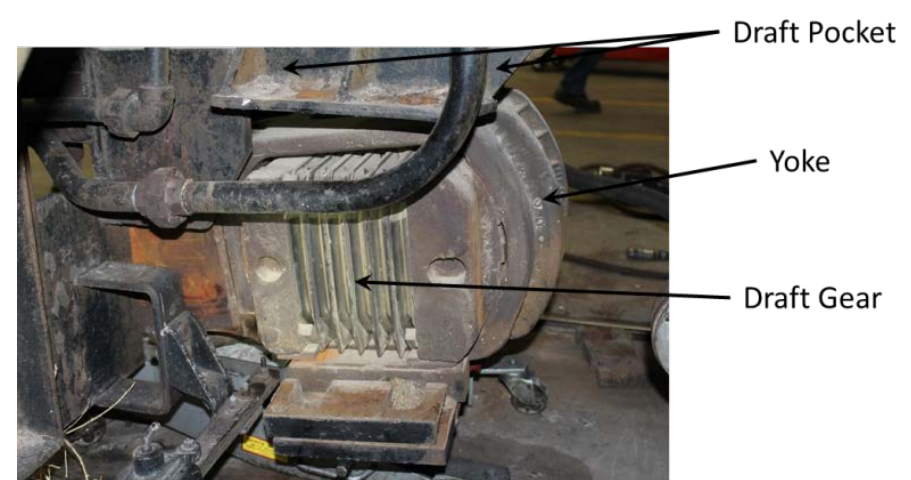

Figure 3. F40 locomotive draft gear and yoke

A photograph of the M1 cab car that will be used in the conventional coupling tests is shown in Figure 4. As can be seen in the photograph, this M1 cab car (\#9324) exhibits damage from a small fire. However, the structural elements of the end frame are unharmed and intact and the rest of the vehicle is undamaged.

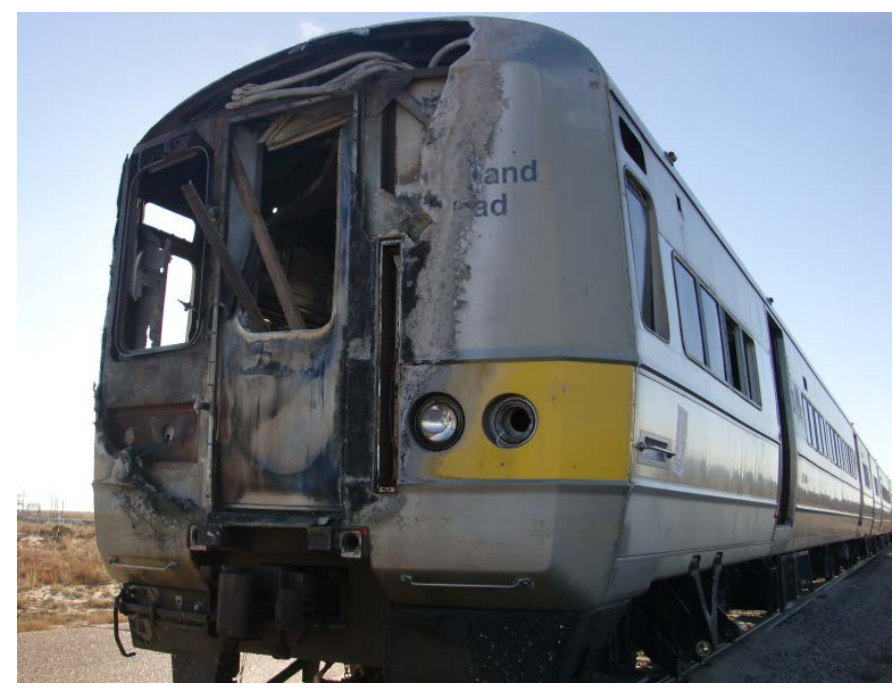

Figure 4. M1 cab car \#9324 with some fire damage.

Figure 5 shows the M1 draft gear and yoke. The draft gear is single acting, so there are two sets of rubber/metal plates. One pack acts in buff and the other acts in draft. These are key elements to be tested in the coupling tests. The load imparted to the cab car underframe is a function of the draft gear stiffness, as well as of the stiffness of the structure that supports the draft gear. Like the locomotive's components, these cab car components will be highly loaded during the test.

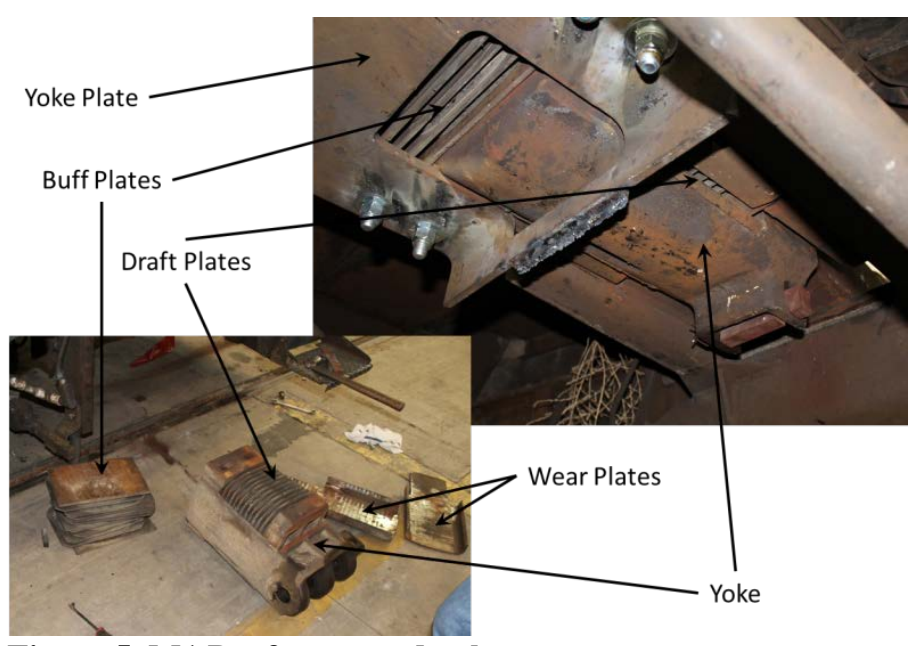

Figure 5. M1 Draft gear and yoke

\section{OVERVIEW OF IMPLEMENTATION}

Measurements are to be made with accelerometers, displacement transducers, and high speed video cameras. This instrumentation is intended to capture the gross motions of the equipment, the relative motion of the couplers and draft gear, and the sequence of events, e.g., coupling, stroking of the draft gears, and eventual damage. The coupling speed of the locomotive will be measured with radar and a reflector-based sensor.

Damage to the equipment in the test can potentially occur in three different modes: structural damage, incipient override, and derailment. Structural damage potentially could include local damage to the buff stops, yokes, or couplers, and global damage to the underframe. Incipient override may occur if the couplers act as a vaulting mechanism. This seems most likely to potentially occur if there is some vertical misalignment between couplers. Similarly, lateral buckling and derailment may occur if the couplers act as a prying mechanism. This seems most likely to potentially occur if there is some lateral misalignment between couplers. Efforts will be made to keep the couplers as closely aligned as possible, so that the likely mode is structural damage.

\section{Accelerometers}

Figure 6 shows a schematic illustration of the accelerometer locations planned for the M1 car. Similar locations are planned for the F40 locomotive. The accelerometers on the carbody are intended to capture the three dimensional gross motions of the carbody - longitudinal, lateral, vertical accelerations, as well as yaw, pitch, and roll. For each test, the measured longitudinal accelerations will be used to calculate impact forces, as well as the equipment velocities and displacements.

This material is declared a work of the U.S. Government and is not subject to copyright protection in the United States.

Approved for public release; distribution is unlimited. 


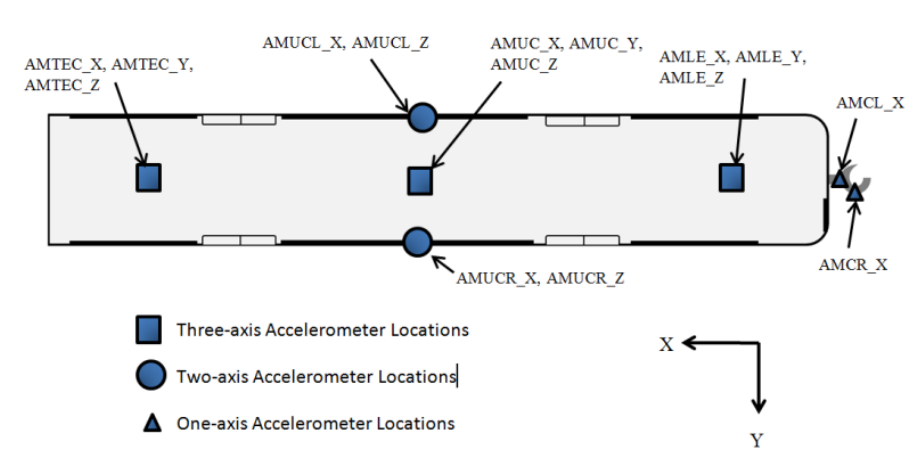

Figure 6. Schematic illustration of M1 cab car accelerometer locations

Figure 7 shows a photograph illustrated with the locations for the accelerometers on the coupler. Both accelerometers will measure longitudinal acceleration. Accelerometers are planned for corresponding locations on the M1 cab car.

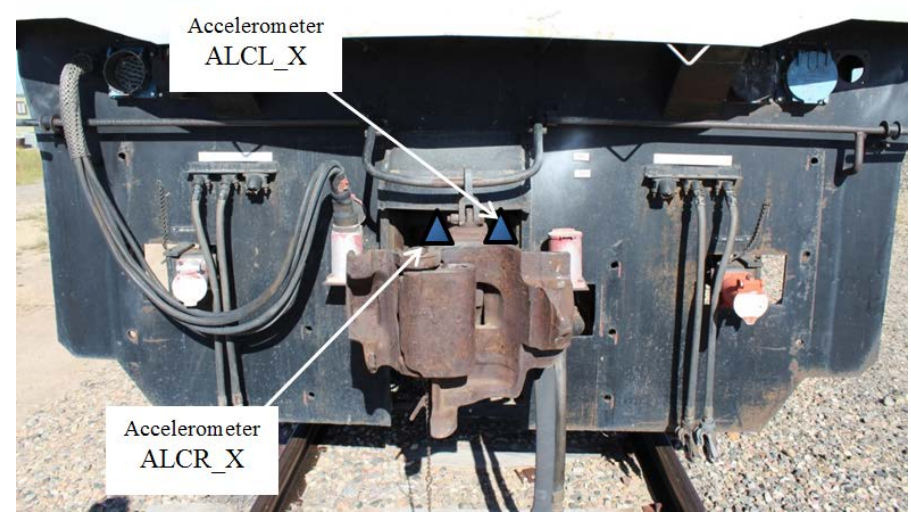

Figure 7. Photograph of locations planned for F40 locomotive coupler longitudinal accelerometers.

Table 1 lists all of the accelerometers for the M1 car. There are a total of seventeen accelerometers. Seventeen accelerometers will also be placed on the F40 locomotive, in corresponding locations.

Table 1. M1 Accelerometer Names, Ranges, and Locations

\begin{tabular}{|c|c|c|}
\hline Name & Range & Location \\
\hline$A M L E \_X$ & $400 \mathrm{~g}$ & lead end, center - longitudinal \\
\hline$A M L E_{-} Y$ & $200 \mathrm{~g}$ & lead end, center - lateral \\
\hline$A M L E \_Z$ & $200 \mathrm{~g}$ & lead end, center - vertical \\
\hline$A M U C_{-} X$ & $200 \mathrm{~g}$ & underframe center - longitudinal \\
\hline$A M U C_{-} Y$ & $200 \mathrm{~g}$ & underframe center - lateral \\
\hline$A M U C_{-} Z$ & $200 \mathrm{~g}$ & underframe center - vertical \\
\hline AMUCR_X & $200 \mathrm{~g}$ & $\begin{array}{l}\text { underframe center right - } \\
\text { longitudinal }\end{array}$ \\
\hline AMUCR_Z & $200 \mathrm{~g}$ & underframe center right - vertical \\
\hline AMUCL_X & $200 \mathrm{~g}$ & $\begin{array}{l}\text { underframe center left } \\
\text { longitudinal }\end{array}$ \\
\hline AMUCL_Z & $200 \mathrm{~g}$ & underframe center left - vertical \\
\hline AMTEC_X & $200 \mathrm{~g}$ & trailing end, center - longitudinal \\
\hline
\end{tabular}

\begin{tabular}{|c|c|l|}
\hline$A M T E C_{-} Y$ & $200 \mathrm{~g}$ & trailing end, center - lateral \\
\hline$A M T E C_{-} Z$ & $200 \mathrm{~g}$ & trailing end, center - vertical \\
\hline$A M L T \_Z$ & $400 \mathrm{~g}$ & lead truck - vertical \\
\hline$A M T T_{-} Z$ & $400 \mathrm{~g}$ & trailing truck \\
\hline$A M C R \_X$ & $5000 \mathrm{~g}$ & coupler, right \\
\hline$A M C L \_X$ & $5000 \mathrm{~g}$ & coupler, left \\
\hline
\end{tabular}

\section{Displacement Transducers}

Figure 8 shows a photograph illustrated with the planned locations for the displacement transducers. Relative vertical, lateral, and longitudinal displacements are to be measured. Corresponding measurements are to be made of the locomotive coupler. These measurements are intended to capture the longitudinal response of the draft gear, and any motions that may lead to lateral buckling or override.

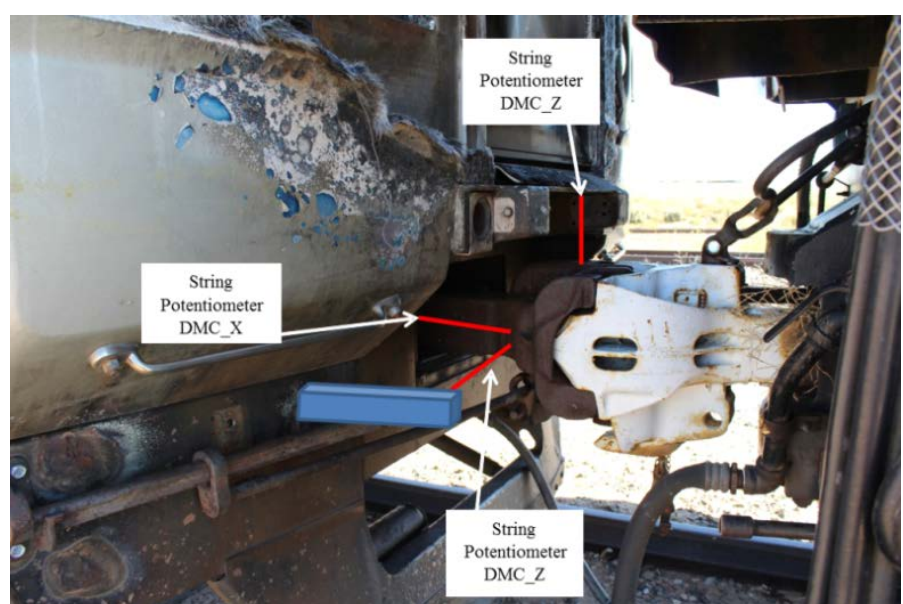

Figure 8. Photograph of locations planned for M1 cab car coupler longitudinal displacement transducers.

Figure 9 shows a photograph illustrated with the planned location for the longitudinal displacement transducer intended to measure potential M1 center sill deformation. A corresponding transducer is planned for the F40, to measure potential deformation of the locomotive draft gear box.

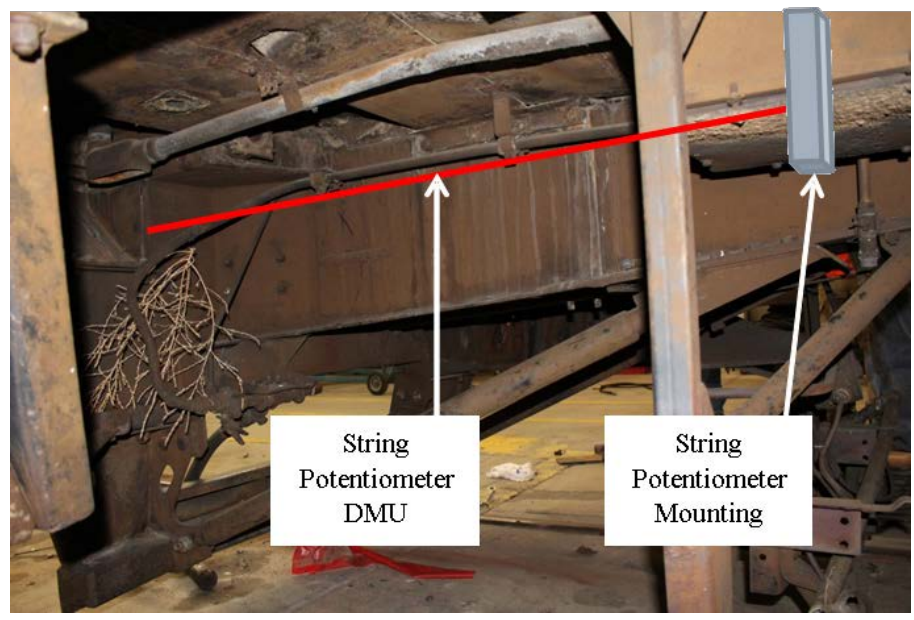

Figure 9. Photograph of locations planned for M1 cab car end structure longitudinal displacement transducers.

This material is declared a work of the U.S. Government and is not subject to copyright protection in the United States.

Approved for public release; distribution is unlimited. 
Table 2 lists all of the displacement transducers to be placed on the M1 car. In addition to the coupler and underframe transducers, the vertical displacements of the secondary suspension will also be measured. The intent is to capture any pitching motion of the M1 car. Measurements in corresponding locations are also planned for the F40 locomotive.

Table 2. M1 Displacement transducer Names, Ranges, and

\begin{tabular}{|c|c|l|}
\hline Name & Range & \multicolumn{1}{|c|}{ Location } \\
\hline$D M L T R$ & $+/-5$ inch & $\begin{array}{l}\text { secondary suspension, lead truck, } \\
\text { right }\end{array}$ \\
\hline$D M L T L$ & $+/-5$ inch & $\begin{array}{l}\text { secondary suspension, lead truck, } \\
\text { left }\end{array}$ \\
\hline$D M T T R$ & $+/-5$ inch & $\begin{array}{l}\text { secondary suspension, trailing } \\
\text { truck, right }\end{array}$ \\
\hline$D M T T L$ & $+/-5$ inch & $\begin{array}{l}\text { secondary suspension, trailing } \\
\text { truck, left }\end{array}$ \\
\hline$D M U$ & $+5 /-45$ inch & underframe, front - longitudinal \\
\hline$D M C_{-} X$ & $\begin{array}{c}+20 /-30 \\
\text { inch }\end{array}$ & coupler - longitudinal* \\
\hline$D M C_{-} Y$ & $+/-25$ inch & coupler - lateral \\
\hline$D M C_{-} Z$ & $+/-25$ inch & coupler - vertical \\
\hline
\end{tabular}

\section{Locomotive Speed Sensors}

Redundant speed sensors will accurately measure the impact speed of the locomotive when it is within 20 inches of the impact point. The speed trap is a reflector-based sensor. It uses groundbased reflectors separated by a known distance and a vehiclebased light sensor that triggers as the locomotive passes over the reflectors. The last reflector is within $10 \mathrm{in}$. of the impact point. The time interval between passing the reflectors is recorded. Speed is then calculated from distance and time. Backup speed measurement will be made with a handheld radar gun.

\section{Cameras}

Six high frame rate and four conventional frame rate high definition (HD) video cameras will document each test run. Figure 8 shows a schematic of the camera position setup. Final alignment and sighting of the cameras will be done when the locomotive and M1 car are positioned at the impact point prior to the start of test. The positioning of the cameras is shown schematically in Figure 10.

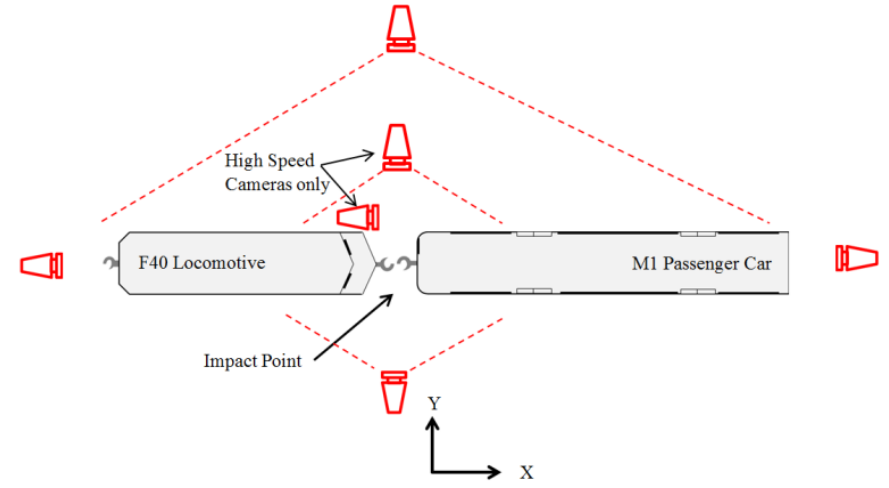

Figure 10. Photograph of locations planned for M1 cab car coupler longitudinal displacement transducers.

\section{$\underline{\text { Test Conduct }}$}

A set of 8-channel battery-powered on-board data acquisition systems will record data from instrumentation mounted on the M1 cab car and the F4 locomotive. These systems provide excitation to the instrumentation, analog antialiasing filtering of the signals, analog-to-digital conversion, and recording of each data stream.

The data acquisition systems are GMH Engineering Data BRICK Model III units. Data acquisition will comply with the appropriate sections of SAE J211. Data from each channel will be anti-alias filtered at $1735 \mathrm{~Hz}$ then sampled and recorded at $12,800 \mathrm{~Hz}$. Data recorded on the Data BRICKS will be synchronized to time zero at initial impact. The time reference will come from closure of the tape switches on the front of the test vehicles. Each Data BRICK is ruggedized for shock loading up to at least $100 \mathrm{~g}$. On-board battery power will be provided by GMH Engineering 1.7 Amp-hour 14.4 Volt NiCad Packs. Tape Switches, Inc., model 1201-131-A tape switches will provide event initial contact.

Software in the Data BRICK will be used to determine zero levels and calibration factors rather than relying on set gains and expecting no zero drift. The Data BRICKS will be set to record 1 second of data before initial impact and 7 seconds data after initial impact.

The tests are to be conducted on tangent track with approximately $0.85 \%$ grade. The locomotive is to be rolled back from the M1 cab car and released. Speed trials will be conducted to determine the distance needed to roll back the locomotive for the desired impact speed. Shortly before each test the release distance will be adjusted based on wind speed and direction.

\section{SIMPLIFIED ANALYSIS}

Figure 11 shows a schematic of a simplified onedimensional two-degree of freedom dynamic model of the coupling test. The M1 cab car is represented by a single mass, and the F40 locomotive is also represented by a single mass. The draft gears act as a spring between the two masses. The model includes the longitudinal braking force acting on the M1. The primary purpose of the model is to estimate the peak force acting between the masses as a function of coupling speed.

A simplified model is appropriate because, while car longitudinal motions strongly influence car vertical and pitch motions, car vertical and pitch motions only weakly influence car longitudinal motions. High longitudinal impact forces and small pitch angles result in significant vertical forces and pitch moments. Small pitch angles only slightly reduce high longitudinal forces.

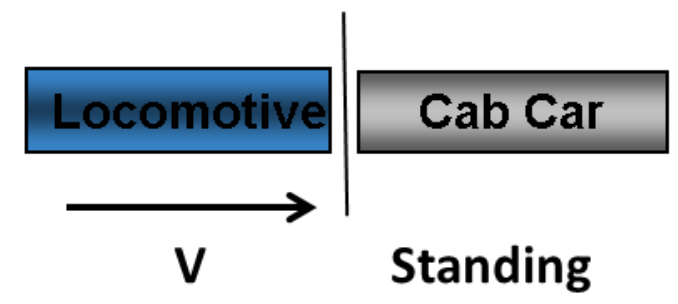

Figure 11. Schematic of one-dimensional two-degree-offreedom lumped parameter coupling model.

This material is declared a work of the U.S. Government and is not subject to copyright protection in the United States. Approved for public release; distribution is unlimited. 
Figure 12 shows the force/displacement characteristics input into the simplified model. The characteristic is that of a relatively soft spring with a relatively hard stop. In such cases, the peak force is sensitive to the stiffness of the stop. Accordingly, a range of bottoming stiffnesses has been analyzed. This bottoming stiffness is a function of both the draft gear itself and the support provided to the draft gear by the locomotive and cab car underframes.

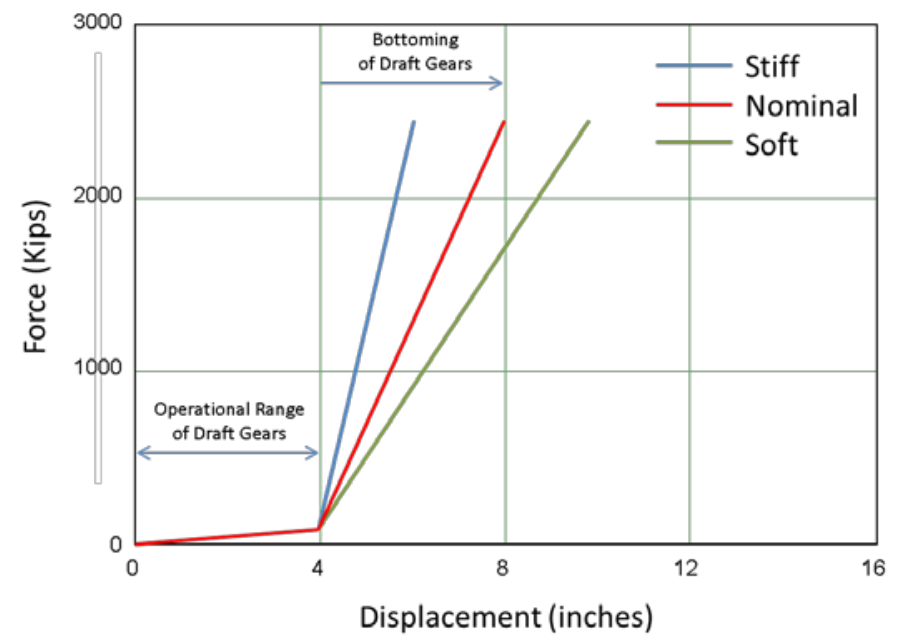

Figure 12. Input force/displacement characteristics for lumped-parameter model.

Figure 13 shows peak coupling force as a function of coupling speed, for the three bottoming stiffnesses. The graph is also annotated with the M1 car elastic strength and crippling strength [9]. The coupler load is predicted to exceed the M1 cab carbody static elastic strength for coupling speeds between 4 and $7 \mathrm{mph}$. The coupler load is predicted to exceed the M1 cab carbody static crippling strength for coupling speeds between 7 and $10 \mathrm{mph}$.

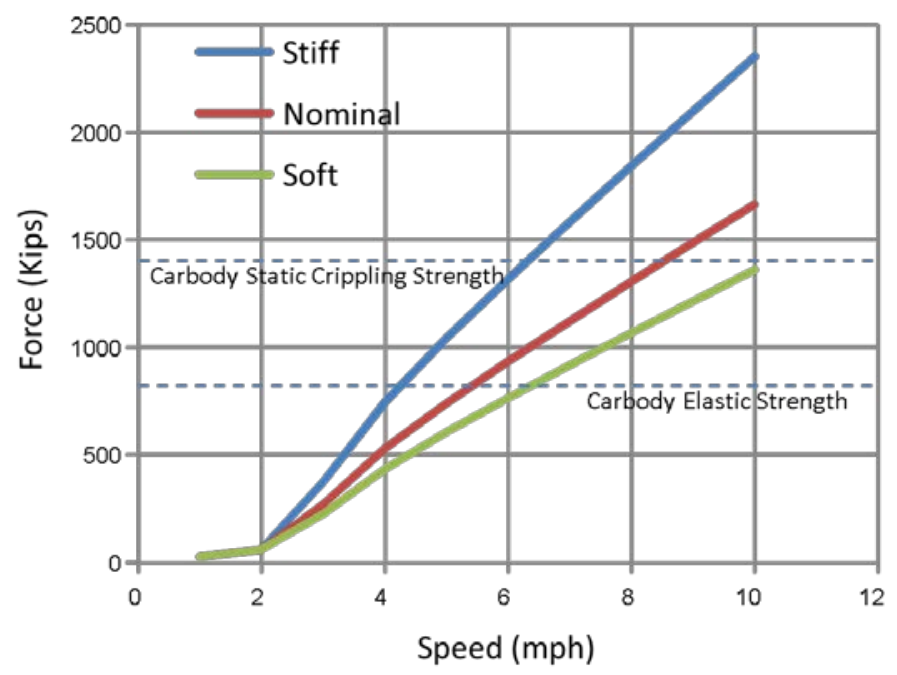

Figure 13. Peak force as a function of coupling speed, results from lumped-parameter model.

\section{SUMMARY}

The FRA, with support of the Volpe Center, is conducting research on the implementation of CEM features on locomotives. These features include pushback couplers and deformable anticlimbers. A series of tests are planned, including coupling tests, car-to-car impact tests, and a train-to-train collision test. This arrangement of tests allows for comparison of conventional with CEM-equipped locomotive measured performance during coupling. Additionally, this arrangement of tests allows for evaluation of the CEM-equipped locomotive performance, as well as comparison of measured with simulated locomotive performance in the car-to-car and train-to-train tests.

In the coupling tests of conventional equipment, the maximum coupling speed for which there is no damage to either vehicle will be measured. A moving locomotive will be coupled to a standing cab car. The coupling speed for the first test will be $2 \mathrm{mph}$, the second test $4 \mathrm{mph}$, and the tests will continue with the speed incrementing by $2 \mathrm{mph}$ until damage occurs. Coupling tests of both conventional and pushback couplers are to be conducted so that the performance of each may be compared. Coupling speeds which lead to equipment damage are to be tested for conventional couplers. Coupling speeds which cause the coupler to trigger are to be tested for pushback couplers.

This paper describes the test requirements and analysis predictions for the coupling tests of conventional equipment. The equipment to be tested, track conditions, test procedures, and measurements to be taken are described. A one-dimensional model for predicting the longitudinal forces acting on the equipment and couplers has been developed, along with preliminary predictions for the conventional coupling tests. It is predicted that damage will occur for coupling speeds between 6 and $8 \mathrm{mph}$.

The conventional coupler test is being carried out, as this paper is being written. Planning is underway for the corresponding pushback coupler tests. Additional papers are planned as additional tests are conducted.

\section{ACKNOWLEDGEMENTS}

This work was performed as part of the Equipment Safety Research Program sponsored by the Office of Research, Development, and Technology of the FRA. The authors appreciate the support and guidance provided by Jeff Gordon, Program Manager, Office of Railroad Policy and Development. Kevin Kesler, Chief of the Equipment and Operating Practices Division, also supported this effort. FRA staff at TTCI helps to coordinate efforts between FRA, Volpe and TTCI. The authors would also like to acknowledge Volpe Center colleagues, Karina Jacobsen and A. Benjamin Perlman for their ongoing technical advice and support in the research discussed in this paper.

\section{REFERENCES}

[1] Mayville, R.A.,Stringfellow, R.G., Rancatore, R.J., Hosmer, T.P., "Locomotive Crashworthiness Research: Executive Summary," DOT/FRA/ORD-95/08, 1995.

[2] Tyrell, D., Severson, K., Marquis, B., Martinez, E., Mayville, R., Rancatore, R., Stringfellow, R., Hammond,

This material is declared a work of the U.S. Government and is not subject to copyright protection in the United States. Approved for public release; distribution is unlimited. 
R., Perlman, A.B., "Locomotive Crashworthiness Design Modifications Study," Proceedings of the 1999 IEEE/ASME Joint Railroad Conference, Institute of Electrical and Electronics Engineers, Catalog Number 99CH36340, 1999.

[3] Mayville, R., Stringfellow, R., Johnson, K., Landrum, S., "Crashworthiness Design Modifications for Locomotive and Cab Car Anticlimbing Systems," US Department of Transportation, DOT/FRA/ORD-03/05, February 2003.

[4] Tyrell, D., Jacobsen, K., Martinez, E., "A Train-to-Train Impact Test of Crash Energy Management Passenger Rail Equipment: Structural Results," American Society of Mechanical Engineers, Paper No. IMECE2006-13597, November 2006.

[5] Llana, P., Stringfellow, R., "Preliminary Development of Locomotive Crashworthy Components," American Society of Mechanical Engineers, Paper No. JRC201156104, March 2011.

[6] Llana, P., Stringfellow, R., "Preliminary Finite Element Analysis of Locomotive Crashworthy Components," American Society of Mechanical Engineers, Paper No. RTDF2011-67006, September 2011.

[7] Llana, P., Stringfellow, R., Mayville, R., "Finite Element Analysis and Full-Scale Testing of Locomotive Crashworthy Components," American Society of Mechanical Engineers, Paper No. JRC2013-2546, April 2013.

[8] Llana, P., "Locomotive Crash Energy Management Test Plans," American Society of Mechanical Engineers, Paper No. JRC2015-5667, March 2015.

[9] Carolan, M., Perlman, B., Tyrell, D., Gordon, J., “Crippling Test of a Budd M-1 Passenger Railcar: Test and Analysis Results,” Proceedings of the 2014 Joint Rail Conference, JRC2014-3824, April 2014.

This material is declared a work of the U.S. Government and is not subject to copyright protection in the United States. Approved for public release; distribution is unlimited. 